\title{
HOW DO WE SEE THE NON LUMINOUS OBJECTS? 12-13 YEARS OLD STUDENTS' MENTAL REPRESENTATION OF VISION
}

\author{
Konstantinos Ravanis \\ University of Patras, Greece \\ Email: ravanis@upatras.gr \\ Accepted: January $6^{\text {th }}, 2018$. Approved: April 2 $2^{\text {nd }}, 2018$. Published: April 29 $9^{\text {th }}, 2018$
}

\begin{abstract}
In this paper, we present the findings of a research which has two objectives: firstly, it recorded 12-13 years old (7th grade) students' mental representation regarding the vision of non-luminous objects, and, secondly, it emphasized on the relative cognitive fields. The research was done through interviews of 107 urban area students in Greece. The students were asked to explain how objects become visible, stressing the following themes: The manner in which our eyes help us see the objects, whether natural or artificial light helps us see the objects and in what way, and if the objects emit light. The data analysis led to the recording of the students' basic mental representation on the one hand, while on the other hand emphasized the reemission or reflection of light by the luminous objects as a basic mental representation. From the research results, it can be concluded that through a teaching intervention based on mental representation we can foster and enhance scientific thinking and learning about light and vision.
\end{abstract}

(C) 2018 Physics Education, UIN Raden Intan, Lampung, Indonesia.

Keywords: light, mental representation, vision, 12-13 years old students

\section{INTRODUCTION}

In the context of Science Education, the question of mental representation of phenomena and concepts in the mind of children of all ages has been studied extensively over the past decades (Küçüközer \& Bostan, 2010; Ouasri, 2017; Lemmer, Kriek \& Erasmus, 2018). The knowledge produced by related research is considered important because it allows us to monitor how a student approaches a certain phenomenon or concept, the main difficulties to the comprehension, the eventual influences of teaching interventions in school (Allen \& Kambouri-Danos, 2016; Ampartzaki \& Kalogiannakis, 2016; Meli, Koliopoulos, Lavidas \& Papalexiou, 2016). The present research paper constitutes a study of 12-13 years old children's representation on vision.

\section{THEORETICAL FRAMEWORK}

Human vision is a research subject of various scientific disciplines. Comprehension of the mechanism of vision from a Science or Physics
Education perspective is equally interesting in terms of studying students' mental representation, as well as within the framework of Optics teaching. Truly, the reasonings based on which students interpret the mechanism of vision are determined by the mental representation of light as an autonomous entity in space that is transmitted independently of the light source and the final receiver (Ravanis, 2012). The question of children's minds representation of all ages of concepts and phenomena of physics and especially in geometrical optics, has been studied extensively over the past decades (Dedes \& Ravanis, 2009a,b; Gallegos Cázares, Flores Camacho \& Calderón Canales, 2009; Tekos \& Solomonidou, 2009; Métioui \& Trudel, 2010, 2012; Valanides, \& Efthymiou, 2012; Castro, 2013; Ntalakoura \& Ravanis, 2014; Tsihouridis et al., 2014; Fleck \& Hachet, 2015; Kaltakci-Gurel1, Eryilmaz \& Mc Dermott, 2016, 2017; Herakleioti \& Pantidos, 2016; Rodriguez \& Castro, 2016; Delserieys, Impedovo, Fragkiadaki \& Kampeza, 2017; Impedovo, Delserieys-Pedregosa, Jégou \& 
Ravanis, 2017; Kuo, Won, Zadnik, Siddiqui \& Treagust, 2017; Pantidos, Herakleioti \& Chachlioutaki, 2017; Delserieys, Jegou, Boilevin \& Ravanis, 2018;). The knowledge created by related research is considered significant because it allows us to monitor how a student approaches a certain concept, the main obstacles to its comprehension, the probable inspirations of teaching interventions in the classroom, and the way a child's thought process develops up until childhood. Based on this mental representation, children's reasoning allows us to determine the limits to the effectiveness of experimental activities in which the process of vision assumes a decisive role.

As exhibited in various international researches, students utilize various types of interpretations, explanations, and argumentations when they attempt to explain which natural process or mechanism enables us to see (Selley, 1996; De Hosson, 2004; Dedes, 2005; Anthopoulou \& Ravanis, 2016). Many such interpretations are incompatible with the characteristics of the model used in education, based on which vision occurs when the light is emitted by self-luminous objects and reemitted by non-luminous objects (Ravanis, 2000; Kokologiannaki \& Ravanis, 2012, 2013).

According to the classic taxonomy of Selley (1996), nine different mechanisms have been formulated in the matter of vision:

1. Cooperative Emission: Both the eye and the light source emit light towards the objects.

2. Stimulated Emission: The light reaches the eye and is then retransmitted or causes the emission of a light beam towards the objects.

3. Simple Emission: The eye sends light to the objects.

4. Stimulated Emission with Reflection: The light leaves the light source, reaches the eye, is then retransmitted or provokes a secondary emission towards the objects. The objects then retransmit the light, which returns to the eye.

5. Primary Reception: The light source lights the eye - this model involves primary light sources.

6. Secondary Reception: The light travels from the light source first to the objects, then to the eye - this model involves objects retransmitting light from a primary light source.

7. Secondary Receptor-Emission: The light travels from the light source to the objects, it then "bounces" towards the eye, and the eye then emits something towards the objects.

8. Sea of Light: The light source generally lights the space, and this is the reason why we can see.

9. Dual Illumination: The light source lights both the eye and the objects at the same time.

Broadly, the categories of children's answers are based on descriptive characteristics such as those to which we referred previously. With this illustration, we map different mental representation on the vision which can serve as the basis for the location of cognitive obstacles in the children's thought process. These obstacles render the approach of the phenomenon of vision, using the Geometrical Optics standard, impossible.

Indeed, these representations are often characterized as models. Given that each respective thought entity does not necessarily constitute a mental model, this characterization is excessive. To be sure, we nowadays recognize that, in order for a representation to be classified as a model, it must lead to functions such as description, explanation, and prediction (Genzling \& Pierrard, 1994; Ravanis, 2010). The confusion of mental models with simple mental representation would not be of such significance if it did not obstruct the comprehension of the true 
nature of problems and difficulties. Truly, models are distinguished by an internal structure whose transformation requires special efforts, while simple representation is more easily adapted to scientific model characteristics. Therefore, the exposition of various representations concerning vision, even if encountered in literature in the form of models, does not lead to the conceptualization of critical impediments to teaching.

In the research presented here, we attempted to study students' mental representation concerning vision. However, we prioritized the emphasis on basic obstacles to education instead of describing problems in their thought process.

\section{METHOD}

The research sample included 107 students 12-13 years old (51 boys and 56 girls, average age: 12 years and 8 months), from 7 class (grade 7) of 4 public schools in Patras, an urban area of Greece.These students had chosen courses covering the fundamentals of Optics in grades 5 and 6. The sample only included children volunteers which we found to identify autonomous entity properties within the light, while we did not include children that connected light with light sources and/or their results.

\section{The Research Procedure}

The research of the children's representation was carried out through individual semi-directive interviews which were 10-12 minutes long, in a specifically prepared laboratory space with natural and artificial lighting.

We asked each child to explain how we saw an everyday non-luminous object (a box, a mug, a chair, a ball) and based on their initial answer there followed a conversation. Within the framework of that conversation, we attempted to note the interpretive structure used in order to approach the problem of seeing these objects. Specifically, we asked the children to explain "how our eyes help us see the objects," "whether natural or artificial light help us see the objects and in what way," and, finally, "whether the objects emit light." The interviews were recorded and their analysis was realized based on the transcript of the recording. Simultaneously, an observation protocol was kept for each student. The data processing was carried out based on the transcribed text and the researcher's observation protocols.

\section{RESULTS AND DISCUSSION Results}

During the interview, we posed the children questions asking them to explain the mechanism to which they attribute the ability to see a colorful object, the role of the eyes within that mechanism, the significance of diffuse natural lighting and the possibility of light emission by the objects.

The processing of data collected from the interviews allowed us to discern a series of alternative parameters or relationships between parameters used by children of that age in order to explain the problem of the mechanism of vision. Consequently, we will present three categories of mental representation which were conceptualized based on the data analysis: sufficient, intermediate and insufficient representation.

\section{Sufficient answers}

To begin with, when examined from a descriptive perspective, our findings resemble those of the aforementioned researches. $21.4 \%$ of students (23/107) interpret vision as a process of reflection or reemission of light towards the eyes from objects that receive light rays. Naturally, we do not discern processed mental representation in children's thought; to be sure, these representations would require familiarity with issues such as light absorption or the formation of colors. 
Therefore, based on children's answers, in certain instances, the eyes receive light, whereas in other cases they receive "images," "rays", or "colors". However, the use of reasonings based on the attribution of a "transmitter" and "receiver" role to the objects simultaneously organizes children's thought with functional thoroughness towards the comprehension of the process of vision. Let us examine two relevant conversation examples.

Extract 1: Researcher (R). How are we able to see this mug? Student $\mathbf{7 1}$ (S.71). With our eyes and because there is light. R. So, what exactly takes place that makes us see the mug? S.71. What happens? So... let's say that there is sunlight everywhere... it sheds on the box, and the box sends it around... there is reflection... R. And what about our eyes? S.11. Oh yes... some rays also go towards our eyes so we can see the box...

Extract 2: R. How are we able to see this box? S.16. Light is shed, which has various rays, red, blue, green... the box keeps some of them, while it reflects and turns away others. R. How do our eyes help us see the box? S.16. The radiance reflected by the box goes to our eyes. R. Does the box give out the light? S.16. Not on its own... it only sends away what it cannot withhold... I don't know how to explain how that happens...

\section{Intermediate answers}

We classified answers of 19/107 students in the second category, in which there are references to the role of the objects as "receiver" and "transmitter". However, very often these references remain vague, hesitant, contradictory and confused. In these answers, children sometimes appear to understand the functional role of eyes, while other times they appear not to. Consequently, we present two examples of conversations with the children.
Extract 3: R. Can you explain to me now how we are able to see this chair before us? S.33. How are we able to? We are... because rays of sunlight shed on it. R. What happens then? S.33. Something happens... our eyes can see it. R. Would you like to explain this in more detail... So what do the rays of sunlight do, the chair, the eyes... S.33. The rays, as I told you before, go towards the box and they light it. Then they go away from the box and... that is how we can see it. R. How do they go away from the box? S.33. Umm... they go away from it, and we can see them. $\mathbf{R}$. And what about the eyes... what do the eyes do? S.33. The eyes see the things. R. How do they see them? Umm... the image that is coming is imprinted on them... R. The image? What image? S.33. In this case, for example, the image of the box that we can see. R. Are the rays you told me were going away from the box before and the image the same thing? S.33. No, the rays and the images are two different things.

Extract 4: R. How are we able to see this box? S.46. Certain colors enter our eyes... they are reflected... let's say that all colors except for yellow enter our eyes and in this way we can see it. R. You said they are reflected... what exactly do you mean by that? S.46. The rays are reflected... but are they reflected on the box? R. What do you think? S.46. ... The light that is shed on the box has many colors... some of them stay on the box, and others go away... they are reflected. We can see those that stay in the box. R. How? S.46. We can see them since they stay on the box.

\section{Insufficient answers}

Finally, we classified the largest part of the answers, namely more than 6 out of 10 answers (63/107), in a third category. In the answers belonging to this category, there is no recognition of a systematic relationship between light, objects, and vision. Vision is generally attributed to the 
light that falls on the objects; the eyes, which simply have the potential to observe, can regard the objects when it is lit. We provide a typical example of the conversation (5) that follows.

Conversation 5: R. Do you want to tell me now how we are able to see this ball on the floor? What I mean is, how can we see things? S88. We see it with our eyes. R. What do the eyes do? S88. They look and see. R. Does light do something that helps us see? S88. The light lights. R. What do you mean by that? $\mathbf{S 8 8}$. It comes from the sun, from the lamps... and lights on things. R. I see... and how can we see them? S88. We see them since they are lit. $\mathbf{R}$. Could you explain in a few words what happens with sunlight? S88. Light starts from the sun and, in a few minutes, comes everywhere and so we can see everything. It lights on the desk, the chairs... it lights and, on the ball, that you asked me about. R. Is light leaving the box? S88. From the box? Umm... no, I do not think so... There is not any light in the box... R. Are you thinking something about it? S88. No... light only comes from lamps and the sun.

In the following table (1) we present the allocation of the answers of all the children in the sample in these three categories.

Table 1. The children's answers: categories and frequencies

\begin{tabular}{llcc}
\hline No & Categories & Frequency & Percentage \\
\hline 1 & $\begin{array}{l}\text { Sufficient } \\
\text { answers }\end{array}$ & 23 & $21.5 \%$ \\
2 & $\begin{array}{l}\text { Intermediate } \\
\text { answers }\end{array}$ & 19 & $17.8 \%$ \\
3 & $\begin{array}{l}\text { Insufficient } \\
\text { answers }\end{array}$ & 65 & $60.7 \%$ \\
\hline & Total & 107 & $100 \%$ \\
\hline
\end{tabular}

\section{Discussion}

This research's results appear to confirm up to a certain extent relevant researches' finding, while also highlighting certain differences (Selley, 1996). A significant difference from a qualitative standpoint is the absence of mental representation that ascribes an active role to the eyes, as in our instance we did not encounter children that used such a mental representation concerning eye function. From a qualitative standpoint, the relatively large percentage of children using a sufficient mental representation about vision constitutes an interesting difference. Nevertheless, both of these data could be related to the choice of the sample; namely, students which already grasped light as an entity in space and independent of the light source and the final receiver (Ravanis \& Boilevin, 2009; Castro \& Rodriguez, 2014; Grigorovitch, 2014, 2015).

However, in the case of the research presented in this article, the basic question was not the exploration of mental representation. Truly, in a large number of relevant papers, we can encounter documentation of children's reasonings in which all findings, in a way, are treated as equivalent (Anthopoulou \& Ravanis, 2016). The analysis of empirical material carried out here was based on the effort to approach problems of children's thought that constitute obstacles to the understanding of the vision mechanism. Indeed, as is shown in the results, not all mental representation that was recorded bear the same significance.

If we closely examine reasonings which imply that children encounter difficulties, we observe that all these students that do not sufficiently represent eye function in their thought in no way refer to the process of re-emission or reflection of light on objects; instead, they simply invoke their lighting.

In contrast, those students which refer to reflection face no difficulties in describing the eye as a receiver of light. Therefore, it is meaningless from a teaching standpoint to refer to two different problems faced by students, namely the role of the eyes and the reemission of light from objects. This is so because it appears that reemission constitutes a prerequisite not only for the 
construction of a sufficient mental representation for eye function but also mainly for the very recognition of such a matter.

The same hypothesis could be drawn concerning relevant problems that arise while encountering the interaction between light and objects. The differentiation traced between children that attribute the lighting of objects to diffuse light, and other children that invoke the shedding of light on other objects can be regarded as being less interesting if we examine reasonings of children that think based on the reemission of light. Truly, initial references related to the lighting of objects do not appear to be significant in these reasonings. In contrast, we could argue that recognition of re-emission can also restructure the thought of children whose formulations were ambiguous during the interview's first stage.

\section{CONCLUSIONS}

In this paper, the mental representation of 12-13 years old student concerning the non-luminous objects vision was recorded. The research results showed that, even though the children have experiences with this phenomenon, they encounter significant obstacles during the approach of several of its traits.

The combined use of research findings on light, its reemission by objects, as well as the role of eyes in vision allows us to trace the recognition of re-emission as a fundamental cognitive obstacle in children's thought.

Therefore, within the framework of any teaching related to the mechanism of vision, it is particularly meaningful to turn towards the matter of surpassing this obstacle, as the familiarisation with the phenomenon of reemission allows for both the functional use of light as an autonomous entity, as well as the attribution of a receiving role to the eyes. Besides, the understanding of the matter of vision is greatly significant in the teaching of the entire Optics field. This is true since, on the one hand, there arise issues such as the formation of reflections in mirrors and lenses, as well as the existence of colours, the understanding of which requires the understanding of vision, while, on the other hand, the formation of mental representation in any subject of Optics that are incompatible to scientific models enter the thought process through a single gateway: the eyes.

\section{REFERENCES}

Allen, M., \& Kambouri-Danos, M. (2016). Substantive conceptual development in preschool science: contemporary issues and future directions. Early Child Development and Care, 187(2), 181-191.

Ampartzaki, M., \& Kalogiannakis, M. (2016). Astronomy in Early Childhood Education: a conceptbased approach. Early Childhood Education Journal, 44, 169-179.

Anthopoulou, V.,\& Ravanis, K. (2016). How do we see when the light is not "enough"? Mental representation of pre-service preschool teachers. International Education and Research Journal, 2(8), 30-32.

Castro, D. (2013). Light mental representation of 11-12-year-old students. Journal of Social Science Research, 2(1), 35-39.

Castro, D., \& Rodriguez, J. (2014). 8-9year-old pupils' mental representation of light: teaching perspectives. Journal of Advances in Natural Sciences, 2(1), 40-44.

De Hosson, C. (2004). Contribution à l'analyse des interactions entre histoire et didactique des sciences. Élaboration d'un support d'enseignement $d u$ mécanisme optique de la vision pour l'école primaire et le collège et premiers 
éléments d'évaluation. Université Paris-Diderot - Paris VII, France.

Dedes, C. (2005). The mechanism of vision: Conceptual similarities between historical models and children's representation. Science \& Education, 14, 699-712.

Dedes, C., \& Ravanis, K. (2009a). Teaching image formation by extended light sources: The use of a model derived from the history of science. Research in Science Education, 39(1), 57-73.

Dedes, C., \& Ravanis, K. (2009b). History of science and conceptual change: the formation of shadows by extended light sources. Science \& Education, 18(9), 1135-1151.

Delserieys, A., Impedovo, M.-A., Fragkiadaki, G., \& Kampeza, M. (2017). Using drawings to explore preschool children's ideas about shadow formation. Review of Science, Mathematics and ICT Education, 11(1), 55-69.

Delserieys, A., Jegou, C., Boilevin, J.-M., \& Ravanis, K. (2018). Precursor model and preschool science learning about shadows formation. Research in Science and Technological Education, DOI 10.1080/02635143.2017.1353960.

Fleck, S., \& Hachet, M. (2015). Helios: a tangible and augmented environment to learn optical phenomena in astronomy. In Proceedings of ETOP - Education and Training in Optics and Photonics (pp. 979331-979336), Bordeaux, France: SPIE.

Gallegos Cázares, L., Flores Camacho, F., \& Calderón Canales, E. (2009). Preschool science learning: The construction of representation and explanations about color, shadows, light and images. Review of Science, Mathematics and ICT Education, 3(1), 49-73.
Genzling, J.-C., \& Pierrard, M.-A. (1994). La modélisation, la description, la conceptualisation, l'explication et la prédiction. In J.-L. Martinand (Ed.), Nouveaux regards sur l'enseignement et l'apprentissage de la modélisation en sciences (pp. 47-78). Paris: INRP.

Grigorovitch, A. (2014). Children's misconceptions and conceptual change in Physics Education: the concept of light. Journal of Advances in Natural Sciences, 1(1), 34-39.

Grigorovitch, A. (2015). Teaching optics perspectives: 10-11 year old pupils' representation of light. International Education \& Research Journal, 1(3), 4-6.

Herakleioti, E., \& Pantidos, P. (2016). The contribution of the human body in young children's explanations about shadow formation. Research in Science Education, 46(1), 21-42. Impedovo, M. A., Delserieys-Pedregosa, A., Jégou, C., \& Ravanis, K. (2017). Shadow formation at preschool from a socio-materiality perspective. Research in Science Education, 47(3), 579-601.

Kaltakci-Gurel1, D., Eryilmaz, A., \& McDermott, L. C. (2016). Identifying pre-service physics teachers'misconceptions and conceptual difficulties about geometrical optics. European Journal of Physics, 37(4), 04570535.

Kaltakci-Gurel1, D., Eryilmaz, A., \& McDermott, L. C. (2017). Development and application of a four-tier test to assess pre-service physics teachers'misconceptions about geometrical optics. Research in Science \& Technological Education, 35(2), 238-260

Kokologiannaki, V., \& Ravanis, K. (2012). Mental representation of sixth graders in Greece for the 
mechanism of vision in conditions of day and night. International Journal of Research in Education Methodology, 2(1), 78-82.

Kokologiannaki, V., \& Ravanis, K. (2013). Greek sixth graders mental representation of the mechanism of vision. New Educational Review, 33(3), 167-184.

Kuo, Y. R., Won, M., Zadnik, M., Siddiqui, S., \& Treagust, D. F. (2017). Learning Optics with multiple representation: not as simple as expected. In D. Treagust, R. Duit \& H. Fischer (Eds), Multiple representation in Physics Education. Models and modeling in Science Education, v. 10 (pp. 123-138). Cham: Springer.

Küçüközer H., \& Bostan A. (2010). Ideas of kindergarten students on the Day/Night cycles, the seasons and the moon phases. Journal of Theory and Practice in Education,6(2), 267-280.

Lemmer, M., Kriek, J., \& Erasmus, B. (2018). Analysis of students' conceptions of basic magnetism from a complex systems perspective. Research in Science Education, https://doi.org/10.1007/s11165018-9693-z.

Meli, K., Koliopoulos, D., Lavidas, K., \& Papalexiou, G. (2016). Upper secondary school students' understanding of adiabatic compression. Review of Science, Mathematics and ICT Education, 10(2), 131-147.

Métioui, A., \& Trudel, L. (2010). Evolution of student teachers' conceptions about light following constructivist didactic activities. In M. Nodzynsk \& J. R. Pasko (Dir.). Research in Didactics of the Sciences: Monograph (pp. 249252). Krakov, Poland: Pedagogical University of Krakov.
Métioui, A., \& Trudel, L. (2012). The model of the rectilinear propagation of light and the study of the variation of the size of a shadow. US-China Education Review, 2(9), 173-186.

Ntalakoura, V., \& Ravanis, K. (2014). Changing preschool children's representation of light: a scratch based teaching approach. Journal of Baltic Science Education, 13(2), 191-200.

Ouasri, A. (2017). Analyse des difficultés des élèves marocains de 15-16 ans en résolution de problèmes de mécanique (mouvement et repos, interactions mécaniques et forces, poids et masse). Review of Science, Mathematics and ICT Education, 11(2), 69-92.

Pantidos, P., Herakleioti, E., \&Chachlioutaki, M.-E. (2017). Reanalysing children's responses on shadow formation: a comparative approach to bodily expressions and verbal discourse. International Journal of Science Education, 39(18), 2508-2527.

Ravanis, K. (2000). How do we see objects that reflect light? Experiential mental representation of students of 12-13 years old, about vision. In N. Valanidis (Ed.), Second Panhellenic Conference on Teaching of Science and Application of New Technologies in Education, 1, 214-221. Nicosia: Department of Education, University of Cyprus.

Ravanis, K. (2010). Représentations, Modèles Précurseurs, ObjectsifsObstacles et Médiation-Tutelle : concepts-clés pour la construction des connaissances du monde physique à l'âge de 5-7 ans. Revista Electrónica de Investigación en Educación en Ciencias, 5(2), 1-11.

Ravanis, K. (2012). Représentations des enfants de 10 ans sur le concept de 
lumière: perspectives piagétiennes. Schème - RevistaEletrônica de Psicologia EpistemologiaGenéticas, 4(1), 7084.

Ravanis, K., \& Boilevin, J.-M. (2009). A comparative approach to the representation of light for five-, eight- and ten-year-old children: didactical perspectives. Journal of Baltic Science Education, 8(3), 182-190.

Rodriguez, J., \& Castro, D. (2016). Changing 8-9-year-old pupil's mental representation of light: a metaphor based teaching approach. Asian Education Studies, 1(1), 4046.

Selley, N. J. (1996). Children's ideas on light and vision. International Journal of Science Education, 18(6), 713-723.
Tekos, G., \& Solomonidou, C. (2009). Constructivist learning and teaching of optics concepts using ICT tools in Greek primary school: a pilot study. Journal of Science Education and Technology, 18, 415-428.

Tsihouridis, C., Vavougios, D., Ioannidis, G. S., Alexias, A., Argyropoulos, C.,\& Poulios, S. (2014). Using sensors and data-loggers in an integrated mobile school-lab setting to teach Light and Optics. In Interactive Collaborative Learning (ICL), 2014 International Conference on Interactive Collaborative Learning. Dubai, United Arab Emirates: IEEE Xplore. 439-445.

Valanides, N., \& Efthymiou, I. (2012). Student representation of progressively more complex shadow and penumbra phenomena: a way towards conceptual change. In M. D. Avgerinou, B. Chandler, P. Search, \& M. Terzic (Eds), New horizons in visual literacy (pp. 216-230). Šiauliai, Lithuania: Scientia Educologica. 